\title{
Changes in satisfaction with body in pregnant women participating in physical exercise classes and childbirth classes
}

\begin{abstract}
BACKGROUND
During pregnancy, a woman's body undergoes major transformation contrary to the present ideal image of a slim body shape. Satisfaction with the body is important for a pregnant woman because it is one of the factors that determine her physical and mental well-being. The aim of this study was to compare the changes in the satisfaction with the body in women who regularly participated in physical exercise classes (experimental group) and in women who attended traditional childbirth classes (control group).
\end{abstract}

\section{PARTICIPANTS AND PROCEDURE}

The research included 74 women aged 22-37 years in the second and third trimesters of their first pregnancy. The experimental group consisted of 39 pregnant women who participated in physical exercise classes from the Active Nine Months program for pregnant women. The control group consisted of 36 pregnant women who participated

\begin{abstract}
in typical childbirth classes twice a week. The Body Shape Test for Pregnant Women and the modified version of the Body Satisfaction Scale were used.
\end{abstract}

\section{RESULTS}

After two months, women in both groups perceived their body shape as significantly bigger; the ideal figure became plumper, and the disparity between the actual and the ideal figure increased. Dissatisfaction with torso, motor skills, and appearance did not change in the experimental group; a significant increase of dissatisfaction with appearance and motor skills was observed in the control group.

\section{CONCLUSIONS}

Regular physical exercise helps pregnant women to maintain positive attitudes towards their body.

KEY WORDS

pregnancy; dissatisfaction with body; physical activity

organizations - Department of Tourism and Recreation, Józef Piłsudski University of Physical Education, Warsaw, Poland

AUthors' CONTRibution - A: Study design - B: Data collection - C: Statistical analysis - D: Data interpretation .

E: Manuscript preparation · F: Literature search · G: Funds collection

CORRESPONDING AUthor - Prof. Monika Guszkowska, Department of Tourism and Recreation, Józef Piłsudski University of Physical Education, 34 Marymoncka Str., 00-968 Warsaw, Poland, e-mail: mguszkowska@wp.pl 


\section{BACKGROUND}

During pregnancy, a woman's body undergoes major transformation in shape and weight; thus it becomes contrary to the ideal image of a slim body shape. This can cause significant modification of her body image and self-satisfaction with body (Lederman, 1996; Moore, 1978; Strang \& Sullivan, 1985). Because the modern Western ideal of body associates beauty with a slim body shape, women might perceive their body during pregnancy as more distant from the culturally preferred model. Some studies conducted earlier suggested that pregnant women were worried that they became too fat and they often felt less physically attractive than they were before pregnancy (Fox \& Yamaguchi, 1997; Hofmeyr, Marcos, \& Butchart, 1990; Lederman, 1996). Weight gain, as well as change in body shape and shapes of various body parts, caused dissatisfaction (Lacey \& Smith, 1987; Stein \& Fairburn, 1996; Walker 1998). Goodwin, Astbury, and McMeeken (2000) found that a woman's satisfaction with her body image decreased in early pregnancy as compared to the period before pregnancy. Comparative and prospective analyses suggested that body image deteriorated in consecutive months as a result of weight gain during pregnancy (Fairburn, Stein, \& Jones, 1992).

The results obtained by Richardson (1990), in turn, showed that pregnant women perceived changes in their body as temporary and related to the body's adaptation to new tasks. Pregnant women were able to adapt to this change without stress and without a significant decrease in satisfaction with their body. Also, other authors (Abraham, King, \& Llewellyn, 1994; Matsuashi \& Felice, 1991) indicated a positive change: higher self-esteem and acceptance of one's body shape. Recent studies have suggested that most women adapted successfully to change during pregnancy (Clark, Skouteris, Wertheim, Paxton, \& Milgrom, 2009a, 2009b; Skouteris, Carr, Wertheim, Paxton, \& Duncombe, 2005).

A longitudinal study conducted during pregnancy showed that women's images of their bodies were quite stable during this period. Women who were less content with their bodies maintained a lower level of satisfaction in subsequent measurements. During advanced pregnancy, women were the least satisfied with the size of their abdomen, but the dimensions of the ideal body shape also increased with an increase of the body's actual dimensions (Duncombe, Wertheim, Skouteris, Paxton, \& Kelly, 2008).

Not all pregnant women accepted changes in their appearance. Some of them indicated a negative body image. These pregnant women were convinced that they had gained more weight than they should have. Sometimes it was related to negative comments from society (Clark et al., 2009b). The period in which the majority of women experience dissatisfaction with their body is the time following the birth of the child (Clark et al., 2009a, 2009b; Rallis, Skouteris, Wertheim, \& Paxton, 2007).

Satisfaction with body image of a pregnant woman is important because it is one of the factors that determine her physical and mental well-being. A negative body image can lead a pregnant woman to an unhealthy diet, to refraining from eating, or to purging. As indicated by the results of research by DiPietro, Millet, Costigan, Gurewitsch, and Caulfield (2003), one-fifth of pregnant women applied at least one behavior aimed at maintaining weight; negative attitudes toward weight gain were noted in women who gained very little weight during pregnancy. Consequently, a woman's lack of acceptance of her appearance may lead to inappropriate weight gain, premature birth, low birth weight, delayed development of the child, and in extreme cases, to fetal death (Franko \& Walton, 1993; Shearer, 1980). Women who worried the most about their appearance were at the highest health risk: they most frequently dieted, smoked cigarettes, and undertook other actions that were potentially harmful to health (Duncombe et al., 2008).

Lack of satisfaction with the body is associated with a higher indicator of depression (Anderson, Fleming, \& Steiner, 1994); a more positive body image was correlated with a more positive attitude towards pregnancy, as well as lower levels of depression and anger (DiPietro et al., 2003). A negative body image in the third trimester was correlated with disorders in a mother's attachment to her unborn child (Huang, Wang, \& Chen, 2004), and with longer and more difficult birth (McCarthy, 1999). In a study by Haedt and Keel (2007), dissatisfaction with the body was not correlated with maternal attachment to the baby, but it was a moderating factor in change to the feeling of attachment usually observed during pregnancy. In women strongly dissatisfied with the body during the consecutive months of pregnancy, the attachment to the child did not increase.

For these reasons, it is important to find ways to maintain a positive body image during pregnancy. Results of observations and research carried out in the general population suggested that people who undertake physical exercise have a more positive body image (Russell, 2002; Smolak, Murnen, \& Ruble, 2000); further, physical exercise can be used to increase a person's acceptance of their own appearance (Cash, 1996; Fisher \& Thompson, 1994; Guszkowska \& Sionek, 2011; Kostanski \& Gullone, 1998).

Few such studies, however, have been carried out among pregnant women. Walker (1998) reported that physical exercise can help in preventing excessive weight gain and thus reduce the distress associated with body weight and dissatisfaction with the body, both during pregnancy and in the postpartum period. Downs, Dinallo, and Kirner (2008) demonstrated
Body satisfaction in pregnant women 
the existence of a relation between physical activity and body satisfaction both during pregnancy and after childbirth. Those women who were physically active before pregnancy were more satisfied with the body during the pregnancy. Body dissatisfaction and physical inactivity were predictors of increased symptoms of depression in successive trimesters of pregnancy and in the postpartum period. Also, in Polish studies pregnant women who participated in physical exercise classes for pregnant women were more satisfied with their body (Płaczkiewicz, 2009).

Marquez-Sterling, Perry, Kaplan, Halberstein, and Signorile (2000) found that body image improved in pregnant women participating in physical exercise classes who prior to pregnancy had led a sedentary lifestyle. The improvement was not observed in the control group. The two groups did not differ from each other in terms of weight gain or adiposity indicators. Comparative studies showed that pregnant women who were exercising had a more positive body image in the $17^{\text {th }}$ and in the $30^{\text {th }}$ week of gestation (Goodwin et al., 2000). Although no statistically significant change in perception of the body was found in the course of pregnancy, in women who exercised a tendency for more positive results was observed.

In comparative studies of women undertaking exercise during pregnancy (Boscaglia, Skouteris, \& Wertheim, 2003), higher degrees of satisfaction with the body were noted among more active women; these women were even more satisfied with their body between weeks 15 and 22 of their pregnancy than during the time preceding pregnancy. In a group of less active women, no such differences were found.

The purpose of this study was to compare the changes that occurred during two months of pregnancy concerning body image, self-acceptance of the body and satisfaction with the body in pregnant women who participated in physical exercise classes for pregnant women and in pregnant women who participated in traditional childbirth classes.

\section{PARTICIPANTS AND PROCEDURE}

\section{PARTICIPANTS}

The study included 74 women aged 22 to 37 years $\left(M_{\text {age }}=29.33, S D=3.85\right)$ in the second $(n=19)$ and the third $(n=55)$ trimester of their first pregnancy, who upon enrollment in the study were between the $25^{\text {th }}$ and $32^{\text {nd }}$ weeks of their gestation $(M=28.89$, $S D=2.85)$. All women had university degrees and lived in Warsaw or its surrounding area; $78.40 \%$ $(n=58)$ of them were married, $21.60 \%(n=16)$ were in common-law relationships but were not officially married; $55.40 \%(n=41)$ did not work at the time of enrollment in the study, and the rest were professionally active. All respondents had been working before pregnancy. Women with multiple pregnancies, prior miscarriages and abnormalities in the present pregnancy were excluded from the research.

The experimental group consisted of 39 pregnant women who participated in physical exercise classes from the Active Nine Months program for pregnant women. They trained twice a week, 50 minutes each time, and were trained by experienced fitness instructors. The program consisted of general developmental exercises including elements of Pilates, yoga and body ball, muscle strength and elasticity exercises, joint mobility exercises, and relaxation and breathing exercises. Data obtained from women participating at least 12 times in the exercise classes over a two-month period were subjected to analysis.

The control group consisted of 36 pregnant women who participated in typical childbirth classes twice a week. The program of such classes focused on learning about pregnancy, labor, the period of puerperium and child development in the infancy period, as well as on developing skills for proper reactions during labor and the care of a newborn. Class duration, which varied depending on the subject, was between 45 and 60 minutes; classes during which the research took place were 50 minutes long. These classes were conducted by midwives in cooperation with gynecologists, pediatricians, and psychologists. Classes were conducted for six weeks. The analysis was applied only to the results of women who took part in at least 10 birthing classes.

The experimental group consisted of pregnant women who enrolled in traditional birthing classes organized by two obstetrics clinics in Warsaw. Women who met the preliminary criteria were offered additional participation in physical exercise classes for pregnant women. A certificate from the woman's physician confirming that there were no contraindications for participating in such classes was an inclusion criterion. Women who met the preliminary criteria but did not accept the offer were allowed to participate in the research project as a core of the control group. Excluded from the control group were persons who regularly exercised at home or already participated in organized physical activities.

Because the group sampling did not fulfill all requirements for randomization, the groups were compared by characteristics relevant to the study. There was a significant difference between groups in terms of the physical activity before pregnancy (Table 1a). Pregnant women in the experimental group had been more physically active before pregnancy. Respondents in both groups did not participate in the exercise program for pregnant women previously and did not exercise systematically at home while pregnant. In the control group, more pregnant women worked at the time of enrollment in the study. 
There were no significant differences between groups in terms of age, trimester and week of pregnancy, marital status and self-ratings of health and physical fitness (Table 1a and 1b).

\section{MATERIALS AND PROCEDURE}

The Body Shape Test for Pregnant Women, which was developed especially for this research, was used to assess the body image and the degree of body self-acceptance. The test was developed on the model of the most popular tool for measuring satisfaction with the body, the Figure Rating Scale, developed by Stunkard, Sorenson, and Schlusinger (1983). Like that scale, the test depicted nine female bodies with different body shapes varying from very thin to overweight. In the version designed for pregnant women, the shapes of the bodies presented an enlarged abdomen. Respondents chose a figure closest to their actual appearance (the actual figure) and a figure that they wished to have (the ideal figure). The index of the degree of disparity between the actual and ideal figure was calculated (the ideal figure - the actual figure). An index with a negative value showed that a person wished to be slimmer, while an index with a positive value meant that a person wanted to have a plumper shape. The test-retest absolute stability of the original version, which was determined after a two-week period, was satisfactory (0.71). The test-retest stability of the version for pregnant women after eight weeks was satisfactory (actual figure: 0.84, ideal figure: 0.69).

The Body Satisfaction Scale (BSS), which was developed by Slade, Dewey, Newton, Brodie, and Kiemle (1990), was used in order to determine levels of dissatisfaction with the body. Respondents were asked to indicate the degree of dissatisfaction with specific body parts on a seven-point scale, from 1 (very satisfied) to 7 (very unsatisfied). The original scale contained 16 parts of the body, including eight in the area of the head (shape of the head, face, jaw, teeth, nose, mouth, eyes, and ears) and eight in the area of the body (shoulders, neck, chest, abdomen, arms, hands, feet, and legs). The version used in this study was supplemented with the general features of body described as the general appearance (height, weight, figure, and overall physical attractiveness), and the characteristics associated with fitness defined as motor skills (dexterity, flexibility, endurance, strength, agility, and speed). The indices of dissatisfaction with

Table 1a

Socio-demographic characteristics of the experimental group and the control group

\begin{tabular}{|c|c|c|c|}
\hline & $\begin{array}{c}\text { Experimental group } \\
n(\%)\end{array}$ & $\begin{array}{c}\text { Control group } \\
n(\%)\end{array}$ & $\chi^{2}$ \\
\hline $\begin{array}{l}\text { Trimester of pregnancy: } \\
\text { second } \\
\text { third }\end{array}$ & $\begin{array}{l}10(25.60) \\
29(74.40)\end{array}$ & $\begin{array}{r}9(25.70) \\
26(74.30)\end{array}$ & 0.00 \\
\hline $\begin{array}{l}\text { Marital status: } \\
\text { married } \\
\text { unmarried }\end{array}$ & $\begin{array}{r}32(82.10) \\
7(17.80)\end{array}$ & $\begin{array}{r}26(74.30) \\
9(25.70)\end{array}$ & 2.01 \\
\hline $\begin{array}{l}\text { Physical activity before pregnancy: } \\
\text { active } \\
\text { inactive }\end{array}$ & $\begin{array}{l}25(64.10) \\
14(35.90)\end{array}$ & $\begin{array}{l}12(34.30) \\
23(65.70)\end{array}$ & $6.56^{\mathrm{a}}$ \\
\hline $\begin{array}{l}\text { Employment during pregnancy: } \\
\text { yes } \\
\text { no }\end{array}$ & $\begin{array}{l}13(33.30) \\
26(66.70)\end{array}$ & $\begin{array}{l}20(57.10) \\
15(42.90)\end{array}$ & $4.23^{b}$ \\
\hline
\end{tabular}

${ }^{\mathrm{a}} p<.051 ;{ }^{\mathrm{b}} p<.050$

Table $1 \mathrm{~b}$

Socio-demographic characteristics of the experimental group and the control group

\begin{tabular}{lccc}
\hline & Experimental group & Control group & \multicolumn{2}{c}{ ANOVA } \\
& $M(S D)$ & $M(S D)$ & $F$ \\
\hline Age & $29.59(3.65)$ & $28.83(4.09)$ & 0.72 \\
Week of gestation & $28.92(2.20)$ & $28.86(2.40)$ & 0.02 \\
Self-rating of physical fitness & $3.72(0.65)$ & $3.60(0.69)$ & 0.54 \\
Self-rating of health & $4.08(0.58)$ & $4.00(0.54)$ & 0.35 \\
\hline
\end{tabular}

Body satisfaction in pregnant women 
the face, torso, appearance, and motor skills were applied. Because each time the sum of points obtained in a scale was divided by the number of items that comprised the scale, the theoretical variation of all the indices was 1-7. Reliability coefficients of the original version were in the range of 0.79-0.89 (Slade et al., 1990). The test-retest absolute stability of the modified version was satisfactory (face: 0.698 , torso: 0.675, appearance: 0.749 , motor skills: 0.727 ).

In addition, a questionnaire developed by the auMonika Guszkowska, Marta Langwald thors was used that provided basic information about the study participants (age, marital status, education and job), information about the course of their pregnancy, self-ratings of health and physical fitness on a 5-point Likert scale - from 1 (very poor) to 5 (very good) - as well as information on physical activity before (active - inactive) and during pregnancy (participation in exercise classes for pregnant women, exercise at home).

The personal questionnaire was completed during the first week of classes. The BSS and the Body Shape Test for Pregnant Women were conducted twice: once during the first week of classes, and then again after two months. In the group of pregnant women participating in physical exercise classes, the second round of the aforementioned tests was conducted while the program was still in progress; in the case of participants in childbirth classes, the second test was conducted after the completion of classes.

The research project was accepted by the Senate Committee on Ethics of the Józef Piłsudski University of Physical Education in Warsaw and the Bioethics Committee of the Medical University of Warsaw.

\section{RESULTS}

The univariate analysis of variance (ANOVA) for the pre-test results was performed in order to determine the inter-group differences at the outset. The analysis showed no significant differences among all tested variables (actual figure: $F=0.01, p=.922$; ideal figure: $F=0.01, p=.933$; level of self-acceptance of body: $F=0.00, p=.971$; dissatisfaction with face: $F=1.18, p=.278$; dissatisfaction with torso: $F=0.47$, $p=.498$; dissatisfaction with appearance: $F=3.43$, $p=.068$; dissatisfaction with motor skills: $F=2.18$, $p=.144)$. Thus, the experimental and control groups did not differ in terms of body image and satisfaction with body image in the pre-test (see Table 2; second and fifth columns).

Two-way ANOVA with repeated measures (time $\mathrm{x}$ condition: experimental vs. control) was applied in order to establish the significance of change in the perception of one's body and dissatisfaction with it, and differences depending on the type of the activities undertaken (birthing classes; physical exercise). The relevant data are presented in Table 2 (eighth-tenth columns).
With regards to the real figure, a significant main time effect was discovered - after two months, the pregnant women perceived body shape as significantly plumper. The main group effect and group-bytime interaction were not significant.

Similar results were obtained with regards to the ideal figure: a significant time effect, indicating an increase of ideal body shape over time and negligible main group effect and group-by-time interaction.

The self-acceptance also significantly changed over time - the value of the index significantly decreased, which means a growing discrepancy between the real figure and the ideal one. The main group and groupby-time interaction were not statistically significant.

Dissatisfaction with the face significantly decreased regardless of the condition: a significant main time effect was observed, while the main group effect and the group-by-time interaction were not statistically significant.

No significant effects with regards to dissatisfaction with the torso were confirmed, which means that the dissatisfaction with the body was stable over time and did not differ depending on the group.

With regards to dissatisfaction with the appearance, a significant main time effect and group effect, as well as their interaction, were observed. During the two months of the program, a significant increase in dissatisfaction with general features, such as height, weight, and general attractiveness, was noted. The index of discontent assumed a higher value in the control group. Dissatisfaction with appearance grew only in the control group, while in the experimental group the result did not significantly change.

During two months of pregnancy, dissatisfaction with motor skills increased significantly. Dissatisfaction with motor skills was higher in the control group (main group effect). The group-by-time interaction was not significant.

The analysis of change occurring over the period of time (repeated measures ANOVA) was also conducted separately in the experimental group and the control group. In women participating in physical exercise classes (see Table 2, column four), a significant increase in the real figure, as well as the ideal figure, was noted. The decrease in the acceptance of one's body shape assumed a trend level. Dissatisfaction with the face decreased, whereas other indices of dissatisfaction did not change significantly.

In the control group (see Table 2, column seven), significant increases in the real figure and the ideal figure were noted. A significant decrease in the acceptance of one's body shape was also observed. Dissatisfaction with the face decreased, whereas dissatisfaction with the appearance and dissatisfaction with motor skills increased. Dissatisfaction with the torso did not change.

Comparison of the two groups in the post-test indicated significant differences in dissatisfaction with 


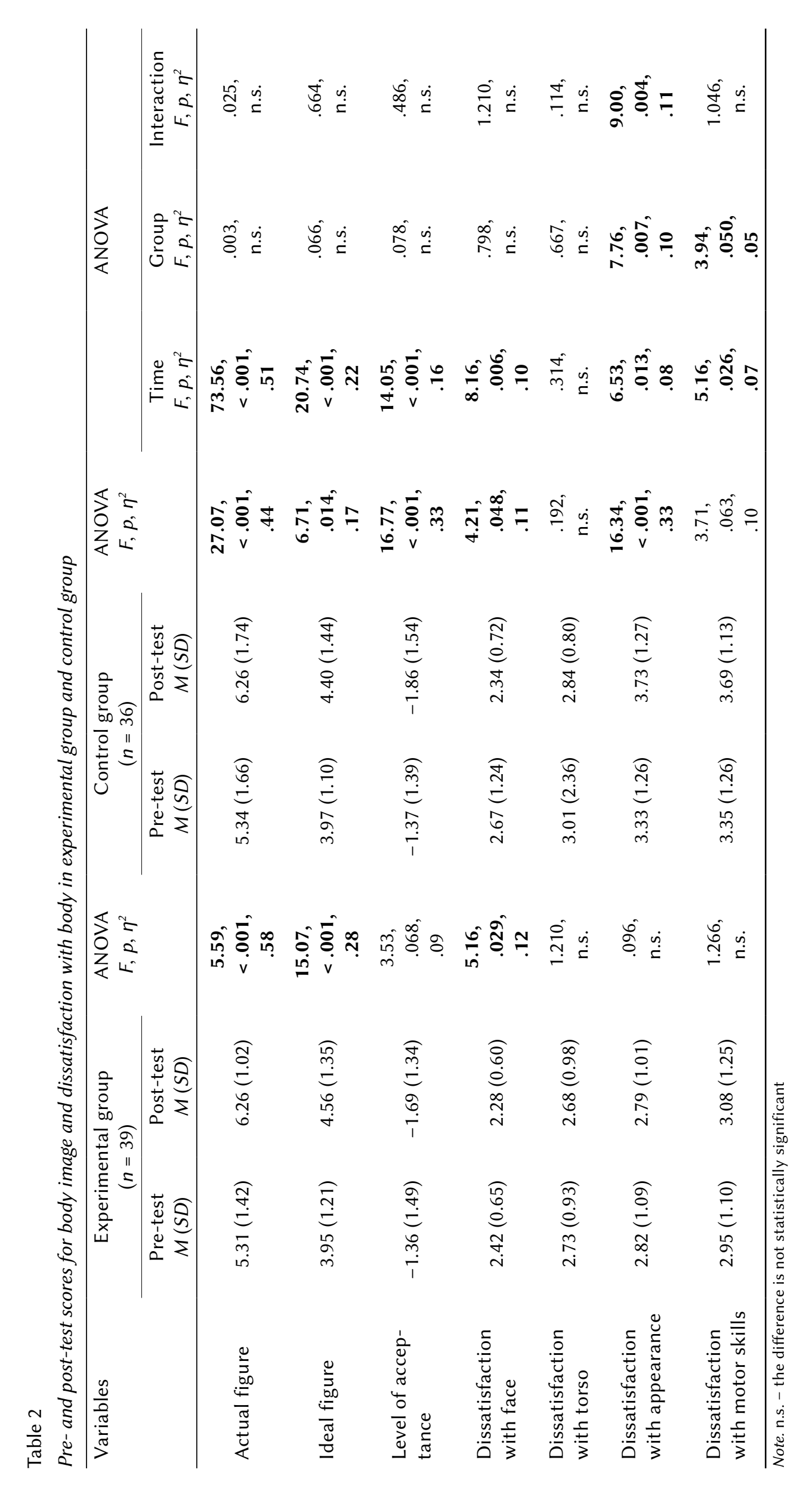

Body satisfaction in pregnant

women 
appearance $(F=12.57, p=.001)$ and dissatisfaction with motor skills $(F=4.85, p=.031)$. There were no significant differences in the real figure $(F=0.00$, $p=.998)$, the ideal figure $(F=0.26, p=.615)$, the discrepancy between them $(F=0.24, p=.624)$, or in dissatisfaction with the face $(F=0.17, p=.679)$ or torso $(F=0.54, p=.466)$. Pregnant women who participated in physical exercise classes after completion of the program showed lower levels of dissatisfaction with their appearance and motor skills.

Monika

Guszkowska,

Marta Langwald

The results of the study confirmed previous observations (Clark et al., 2009a, 2009b; Richardson, 1990; Skouteris et al., 2005) that to some extent pregnant women adapt to changes in the shape and weight of their body during pregnancy. After two months, the studied pregnant women perceived their figures as significantly larger. This suggested that their body image reflected the real changes that happen in a woman's body during pregnancy. Unfortunately, we did not record an objective assessment of the body shape of the studied women, which would directly determine the extent to which a woman's self-assessment was in accord with reality.

The change in the ideal figure was parallel to the change in the real body shape. After two months, the ideal figure selected by pregnant women in both conditions was significantly plumper. Other researchers also found that in pregnant women the perception of the ideal body shape increases with an increase in the actual size of a woman's body (Duncombe et al., 2008).

In both groups, the chosen figures - the real and the ideal body shape - were similar. The form of activity in which women were participating did not influence the perception of the actual and ideal figure, or the changes that occurred in the body with the progress of pregnancy. It can be noted, however, that while the change in the real body image changed to a similar extent in both groups, the change in the ideal figure was more evident in women attending physical exercise classes. It can be assumed that changes in the ideal figure for the pregnant women attending physical exercise classes "kept up" faster with the changes observed by women in their own bodies, and that the degree of self-acceptance (the disparity between the real figure and the ideal figure) was less reduced.

With the progress of pregnancy, the disparity between the real figure and the ideal figure increased in both groups. This increase was far greater in pregnant women participating in the traditional birthing classes, however, than in women attending physical exercise classes. This suggested that women attending physical exercise classes adapted better to modifications in their own appearance.
Pregnant women represented a relatively low level of dissatisfaction with the body. The level of dissatisfaction was the highest with regards to motors skills and the general features of appearance (including body weight); the smallest level of dissatisfaction concerned the face. This is quite understandable in light of the nature of change that takes place in the body of pregnant woman. In the second and the third trimesters of pregnancy, a significant increase in body weight not only makes a woman's body look different than the existing model of beauty, but also it reduces her physical fitness. In pregnant women, the body's center of gravity is moved slightly forward, which can cause problems with balance. Also, the reception of kinesthetic sensations deteriorates, and the coordination of movements is affected (Treuth, Butte, \& Puyau, 2005). All these factors cause significant changes in the area of motor skills and reduce self-satisfaction with this aspect of a woman's physicality. However, the appearance of the face did not change that much. It is worth noting that during the two months, the index of dissatisfaction with the face in the women participating in the study significantly decreased. Pregnant women became less dissatisfied with their own eyes, ears, nose, etc. This can be interpreted as a kind of compensation mechanism: balancing lower level of satisfaction with physical fitness, body weight, and general physical attractiveness by increasing the level of satisfaction with one's face helps to keep one's general satisfaction with the body at the same level. It is also an expression of effective adaptation to changes in the body during pregnancy. Thus, the results of this study confirmed the results of a study indicating that women maintained a positive body image during pregnancy (Clark et al., 2009a, 2009b; Skouteris et al., 2005).

The changes in indices of dissatisfaction varied depending on the form of activities in which pregnant women were involved. Those pregnant women who attended the exercise classes in the Active Nine Months program maintained the same level of dissatisfaction with their motor skills and appearance, while the level of their satisfaction with the face increased. This is consistent with the results of some previous studies (Haedt \& Keel, 2007). In the group of women involved in traditional childbirth classes, a significant decrease of dissatisfaction with the face was also observed, but the dissatisfaction with overall appearance and motor skills increased. This, in turn, confirmed the claims of other authors (Fairburn et al., 1992) that body image gets worse in the consecutive months of pregnancy.

Based on the observed differences, it can therefore be concluded that physical exercise may help to maintain women's satisfaction with physicality during pregnancy. It should be noted that at the beginning of the program, the two groups did not differ in the indices of dissatisfaction with different aspects 
of the body. After two months, pregnant women participating in physical exercise classes showed significantly lower levels of dissatisfaction with appearance and motor skills than respondents in the control group. The obtained results were consistent with the results of previous studies, both comparative and implemented in an experimental model. In comparative research positive relationships between physical activity and body satisfaction were found, both during pregnancy and after delivery, and greater satisfaction with the body in women who were physically active during pregnancy was noted (Boscaglia et al., 2003; Goodwin et al., 2000; Płaczkiewicz, 2009; Downs et al., 2008). The experimental research showed in particular that participants of exercise programs for pregnant women improved their body image, which was not observed in the control group (Marquez-Sterling et al., 2003).

Physical activity may help to maintain satisfaction with one's body through both physiological and psychological mechanisms. The results of research showed that physical exercise during pregnancy contributed to reducing the risk of excessive weight gain in pregnant women, facilitated adaptation to changes associated with a shift in the center of gravity, and improved motor coordination. Physical activity increases the awareness of one's body, and forces one to assume the right posture; exercise teaches self-awareness of the body, strengthens muscles, and improves flexibility (Weissgerber, Wolfe, Davies, \& Mottola, 2006; Haakstad \& Bo, 2011). These benefits enable pregnant woman to maintain body satisfaction with appearance and motor skills.

Psychological mechanisms enable a pregnant woman to accept change in her body. The coping strategy with changes in body shape during pregnancy might include change in the hierarchy of values which make the well-being of the child more important that aesthetic values. Pregnant women attribute to their body "utility value" and evaluate it in terms of function rather than appearance. The observed weight gain can be interpreted as evidence of the proper course of pregnancy rather than a factor reducing attractiveness (Clark et al., 2009a, 2009b).

An additional source of positive experiences can be gained from reinforcement from the other women in the group attending physical exercise classes as well as from the instructor. Exercise performed in a group of other pregnant women enables a woman to make social comparisons with a more appropriate frame of reference than the beauty model presented in the media, which identifies physical attractiveness with slimness (Boscaglia et al., 2003).

The research presented in this paper has some limitations. First, all the women were well educated, lived in the capital city and had worked before pregnancy. These factors significantly limit the possibility to generalize the results. Second, the assign- ment of participants to the groups did not meet the conditions of randomization, because the respondents chose the group according to their preferences. Women more physically active before pregnancy and less professionally active during pregnancy took part in the physical activity program. Physical activity before pregnancy could influence the decision to participate in the exercise program and increase its effects. However, while tracking the changes under the influence of the intervention program, the baseline levels of dependent variables were the most important, and they did not differ significantly, despite the lack of randomization.

\section{CONCLUSIONS}

According to Haedt and Keel (2007), dissatisfaction with the body should be an important subject of intervention in pregnant women, because it is related to the health of the mother and the fetus. The results of the present study suggested that one way of such intervention would be to engage women in physical exercise programs for pregnant women. The results of this study provide support for the hypothesis that regular exercise helps to maintain a positive attitude towards a body that is increasing in size with the progress of pregnancy. Exercise can be a kind of adaptive strategy to the changes in the body of a pregnant woman. Any possible negative feelings connected with the weight gain might be balanced with the positive feelings associated with exercise (Cash, 1996). In addition, physical exercise preventing excessive weight gain and a decline in physical function enables a pregnant woman to maintain her satisfaction with the body and its functions, thus contributing to her physical and mental well-being.

The research was financed under project no. NN 404 017838, "The influence of pregnant women's physical activity on their mental and physical health, the course of pregnancy, and childbirth," by the Ministry of Science and Higher Education in Poland.

\section{References}

Abraham, S., King, W., \& Llewellyn, J. (1994). Attitudes to body weight, weight gain and eating behavior in pregnancy. Journal of Psychosomatic Obstetrics and Gynaecology, 15, 189-195.

Anderson, V. N., Fleming, A. S., \& Steiner, M. (1994). Mood and the transition to motherhood. Journal of Reproductive and Infant Psychology, 12, 69-77.

Boscaglia, N., Skouteris, H., \& Wertheim, E. H. (2003). Changes in body image satisfaction during pregnancy: A comparison of high exercising and low exercising women. Australian and New Zealand Journal of Obstetrics and Gynaecology, 43, 41-45.
Body satisfaction in pregnant women 
Cash, T. F. (1996). The treatment of body image disturbance. In: J. Thompson (ed.), Body image, eating disorders, and obesity: an integrative guide for assessment and treatment (pp. 83-107). Washington: APA.

Clark, A., Skouteris, H., Werthei, E. H., Paxton, S. J., \& Milgrom, J. (2009a). The relationship between depression and body dissatisfaction across pregnancy and the postpartum: A prospective study. Journal of Health Psychology, 14, 23-31. DOI: 10.1177/1359105308097940

Monika Guszkowska, Marta Langwald

Clark, A., Skouteris, H., Wertheim, E. H., Paxton, S. J., \& Milgrom, J. (2009b). My baby body: A qualitative insight into women's body-related experiences and mood during pregnancy and the postpartum. Journal of Reproductive and Infant Psychology, 27, 330-345. DOI: 10.1080/02646830903190904

DiPietro, J.A., Millet, S., Costigan, K. A., Gurewitsch, E., \& Caulfield, L. E. (2003). Psychosocial influences on weight gain attitudes and behaviors during pregnancy. Journal of American Dietetic Association, 10, 1314-1319. DOI: 10.1016/S00028223(03)01070-8

Downs, D. S., DiNallo, J. M., \& Kirner, T. L. (2008). Determinants of pregnancy and postpartum depression: Prospective influences of depressive symptoms, body image satisfaction, and exercise behavior. Annals of Behavioral Medicine, 36, 54-63. DOI: $10.1007 / \mathrm{s} 12160-008-9044-9$

Duncombe, D., Wertheim, E. H., Skouteris, H., Paxton, S. J., \& Kelly, L. (2008). How well do women adapt to changes in their body size and shape across the course of pregnancy? Journal of Health Psychology, 13, 503-515. DOI: 10.1177/1359105308088521

Faiburn, C. G., Stein, A., \& Jones, R. (1992). Eating habits and eating disorders during pregnancy. Psychosomatic Medicine, 54, 665-672.

Fisher, E., \& Thompson, J. K. (1994). A comparative evaluation of cognitive behavioral therapy (CBT) versus exercise therapy (ET) for the treatment of body image disturbance: Preliminary findings. Behavior Modification, 18, 171-185.

Fox, P., \& Yamaguchi, C. (1997). Body image change in pregnancy: A comparison of normal weight and overweight primigravidas. Birth, 24, 35-40.

Franko, D. L., \& Walton, B. E. (1993). Pregnancy and eating disorders: a review and clinical implications. International Journal Eating Disorders, 13, 41-47.

Goodwin, A., Astbury, J., \& McMeeken, J. (2000). Body image and psychological well-being in pregnancy. A comparison of exercisers and non-exercisers. Australian and New Zealand Journal of $\mathrm{Ob}^{-}$ stetrics and Gynaecology, 40, 442-447.

Guszkowska, M., \& Sionek, S. (2011). Zmiany oceny ciała i nastroju kobiet uczestniczących w trzymiesięcznym programie ćwiczeń tlenowych [Changes in Bodily Self-Esteem and Mood States in Women Participating in Three-Month Aerobic Exercise Program]. Turystyka i Rekreacja, 7, 121-126.
Haakstad, L. A. H., \& Bo, K. (2011). Effect of regular exercise on prevention of excessive weight gain in pregnancy: A randomized control trial. European Journal of Contraception \& Reproductive Health Care, 16, 116-125. DOI: 10.3109/13625187. 2011.560307

Haedt, A., \& Keel, P. (2007). Maternal attachment, depression, and body dissatisfaction in pregnant women. Journal of Reproductive and Infant Psychology, 25, 285-295. DOI: 10.1080/02646830701691327

Hofmeyr, G. J., Marcos, E. F., \& Butchart, A. M. (1990). Pregnant women's perceptions of themselves: A survey. Birth, 17, 205-206.

Huang, H. C., Wang, S. Y., \& Chen, C. H. (2004). Body image, maternal-fetal attachment, and choice of infant feeding method: A study in Taiwan. Birth, 31, 183-188. DOI: 10.111/j.0730-7659.2004.00303.x

Konstanski, M., \& Gullone, E. (1998). Adolescent body image dissatisfaction: relationships with self-esteem, anxiety and depression controlling for body mass. Journal of Child Psychology and Psychiatry, 39, 255-262.

Koniak-Griffin, D. (1994). Aerobic exercise, psychological well-being, and physical discomforts during adolescent pregnancy. Research in Nursing and Health, 17, 253-263.

Lacey, J. H., \& Smith, G. (1987). Bulimia nervosa: The impact of pregnancy on mother and baby. British Journal of Psychiatry, 150, 777-781.

Lederman, R. P. (1996). Psychosocial adaptation in pregnancy: Assessment of seven dimensions of maternal development. New York: Springer.

Marquez-Sterling, S., Perry, A. C., Kaplan, T. A., Halberstein, R. A., \& Signorile, J. F. (2000). Physical and psychological changes with vigorous exercise in sedentary primigravidae. Medicine and Science in Sports and Exercise, 32, 58-62.

Matsuhashi, Y., \& Felice, M. E. (1991). Adolescent body image during pregnancy. Journal of Adolescent Health, 12, 313-315.

McCarthy, M. E. (1999). A longitudinal study of body image and adjustment during pregnancy and the puerperium. Dissertation Abstract International, 60, 0836B.

Moore, D. S. (1978). The body image in pregnancy. Journal of Nurse Midwifery, 22, 17-27.

Płaczkiewicz, M. (2009). Rekreacja ruchowa a poziom optymizmu oraz obraz własnego ciała kobiet ciężarnych [Physical recreation and the level of optimism and body image among pregnant women]. In: M. Guszkowska (ed.), Aktywność ruchowa kobiet. Formy, uwarunkowania, korzyści i zagrożenia [Physical activity of women. Forms, conditions, benefits and risks] (pp. 325-332). Warszawa: Danmar.

Rallis, S., Skouteris, H., Wertheim, E. H., \& Paxton, S. (2007). Predictors of body image during the first year postpartum: A prospective study. Women \& Health, 45, 87-104. DOI: 10.1300/J013v45n01-06 
Richardson, P. (1990). Women's experiences of body change during normal pregnancy. Maternal and Child Nursery Journal, 19, 93-111.

Russell, W. D. (2002). Comparison of self-esteem, body satisfaction, and social physique anxiety across males of different exercise frequency and racial background. Journal of Sport Behavior, 25, 74-91.

Shearer, M. H. (1980). Malnutrition in middle class pregnant women. British Family Journal, 7, 27-35.

Skouteris, H., Carr, R., Wertheim, E. H., Paxton, S. J., \& Duncombe, D. (2005). A prospective study of factors that lead to body image dissatisfaction during pregnancy. Body Image, 2, 347-361. DOI: 10.1016/j.bodyim.2005.09.002

Slade, P. D., Dewey, M. E., Newton, T., Brodie, D., \& Kiemle, G. (1990). Development and preliminary validation of the body satisfaction scale (BSS). Psychology and Health, 4, 213-220.

Smolak, L., Murnern, S. K., \& Ruble, A. E. (2000). Female athletes and eating problems: A meta-analysis. International Journal of Eating Disorders, 27, 371-380.

Stein, A., \& Fairburn, C. G. (1996). Eating habits and attitudes in the postpartum period. Psychosomatic Medicine, 58, 321-325.

Strang, V. R., \& Sullivan, P. L. (1985). Body image attitudes in pregnancy and the postpartum period. Journal of Obstetrics, Gynaecology and Neonatal Nursery, 14, 332-337.

Stunkard, A. J., Sorenson, T., \& Schlusinger, F. (1983). Use of Danish adoption registers for the study of obesity and thinness. In: S. S. Kety, L. P. Rowland, R. L. Sidman, \& S. W. Mathysse (eds.), The genetics of neurological and psychological disorders (pp. 115-120). New York: Raven Press.

Treuth, M. S., Butte, N. F., \& Puyau, M. (2005). Pregnancy-related changes in physical activity, fitness, and strength. Medicine and Science in Sports and Exercise, 37, 832-837.

Walker, L. O. (1998). Weight-related distress in the early month after childbirth. Western Journal of Nursery Research, 20, 30-44.

Weissgerber, T. L., Wolfe, L. A., Davies, G. A. L., \& Mottola, M. F. (2006). Exercise in the prevention and treatment of maternal-fetal disease: a review of the literature. Applied Physiology, Nutrition and Metabolism, 31, 661-674. DOI: 10.1139/H06-060 